\title{
Survey on Ten Years of Multi-Depot Vehicle Routing Problems: Mathematical Models, Solution Methods and Real-Life Applications
}

\author{
D. G. N. D. Jayarathna ${ }^{1}$, G. H. J. Lanel ${ }^{2} \&$ Z. A. M. S. Juman ${ }^{3}$ \\ ${ }^{1}$ Colombo International Nautical and Engineering College, Sri Lanka \\ ${ }^{2}$ Department of Mathematics, University of Sri Jayewardenepura, Sri Lanka \\ ${ }^{3}$ Department of Mathematics, Faculty of Science, University of Peradeniya, Peradeniya, Sri Lanka \\ Correspondence: D. G. N. D. Jayarathna, Colombo International Nautical and Engineering College, Sri Lanka
}

Received: January 29, 2021 Accepted: February 10, 2021 Online Published: February 27, 2021

\begin{abstract}
A crucial practical issue encountered in logistics management is the circulation of final products from depots to end-user customers. When routing and scheduling systems are improved, they will not only improve customer satisfaction but also increase the capacity to serve a large number of customers minimizing time. On the assumption that there is only one depot, the key issue of distribution is generally identified and formulated as VRP standing for Vehicle Routing Problem. In case, a company having more than one depot, the suggested VRP is most unlikely to work out. In view of resolving this limitation and proposing alternatives, VRP with multiple depots and multi-depot MDVRP have been a focus of this paper. Carrying out a comprehensive analytical literature survey of past ten years on cost-effective Multi-Depot Vehicle Routing is the main aim of this research. Therefore, the current status of the MDVRP along with its future developments is reviewed at length in the paper.
\end{abstract}

Keywords: multi-depot vehicle routing problem, exact methods, heuristic, meta-heuristic

\section{Introduction}

Finding best routes for fleets to reach their customers has been the major focus of VRP - Vehicle Routing Problem which involves calculating the lowest cost delivery directions or paths from a depot to a set of geographically dispersed clients in a crosswise manner. (Jayarathna et al., 2019, Jayarathna et al., 2019,). Even after conducting numerous studies on VRP, so far, no proper application has been found.

Despite many studies conducted based on the VRP, it does not present very realistic applications (see (Modeling of an Optimal Outbound Logistics System (A Contemporary Review Study on effects of Vehicle Routing, Facility Location and Locational Routing Problems) review study on VRPs). This has led more attention on the more realistic scenario MDVRP: Multi-Depot Vehicle Routing Problem, which is a variant of VRP

A. Introduction to Multi-Depot Vehicle Routing Problems

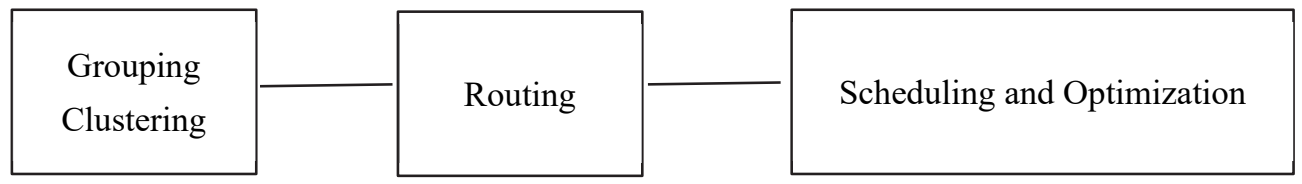

Figure 1.1. MDVRP Plan

As per the concept of Multi-Depot Vehicle Routing Problem (MDVRP), vehicle(s) start and end their route at the same deport and there are multiple depots to start the route. If a vehicle(s) starts the route from deport A, same vehicle complete the assigned route once it is back in depot A. MDVRP being a concept of Single-Depot Vehicle Routing Problem (SDVRP), traditionally focused on minimizing the sum of tour length. This study focusses on the MDVRP with a number of assumptions and constraints.

In broader view, the goal of MDVRP is to minimize the time to reach the customer or in other words to minimize the route distance. Among its various objectives, MDVRP mainly focus on improving the efficient delivery. Less lead time create happy customers Well planned route reduces the travel and well the number of vehicles in operation, ultimately minimizing the operating cost of the operator. The MDVRP, same number of vehicles 
assigned to each deport, while the traditional approach assigned each vehicle to same number of nodes. In the former case i.e. in VRP the results were poor thus this technique is accepted as this gives better results than VRP. In most of the real-life VRPs, demands at the customer nodes vary due to various factors, such as location and temporal seasonal factors. A network routing topology generated by solving min-max MDVRP results in a set of daisy-chain network configurations that minimize the maximum latency between a server and client.

This could be the most favorable and benefited method if the server-client connection cost is high and the clientclient connection cost is low. Each customer's need could vary and only one vehicle should serve the different demands of the same customer. This disable duplicated routes/ vehicles for same customer. There are few considerations which should be kept in mind while implementing MDVRP.

1) Vehicle should begin and stop its route at the depot.

2) A customer is visited exactly once by the vehicle in each cluster.

3) Total cost to traverse the customers is minimized.

In traditional approach all efforts made to minimize the total distance travelled while MDVRP attempts to reduce the maximum distance travelled by the vehicle. To achieve this, customers clusters are identified from the depot. Importantly, total number of designed routes should be less or equal to the number of depots available. This is to make sure distribution has done with the minimum required vehicles and the ultimate objective of the route planning has not being compromised. Customers are assigned to different routes. The customers assign to different routes based on the identified clusters and distance from depot computed based on the below rule;

- If $\mathrm{D}(\mathrm{ci}, \mathrm{A})<\mathrm{D}(\mathrm{ci}, \mathrm{B})$, then customer ci is assigned to $\operatorname{depot} \mathrm{A}$

- If $\mathrm{D}(\mathrm{ci}, \mathrm{A})>\mathrm{D}(\mathrm{ci}, \mathrm{B})$, then customer ci is assigned to depot $\mathrm{B}$

- If $\mathrm{D}(\mathrm{ci}, \mathrm{A})=\mathrm{D}(\mathrm{ci}, \mathrm{B})$, then customer ci is assigned to a depot chosen arbitrarily between $\mathrm{A}$ and $\mathrm{B}$.

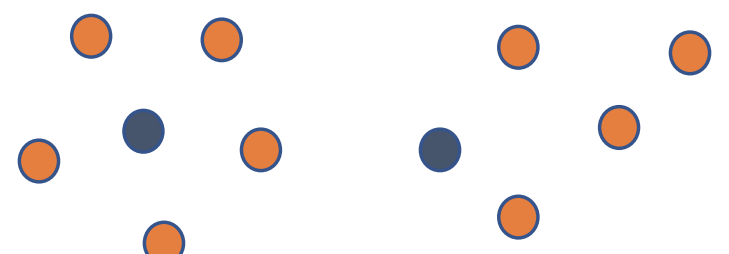

Figure 1.2. Random distribution of cities and depots
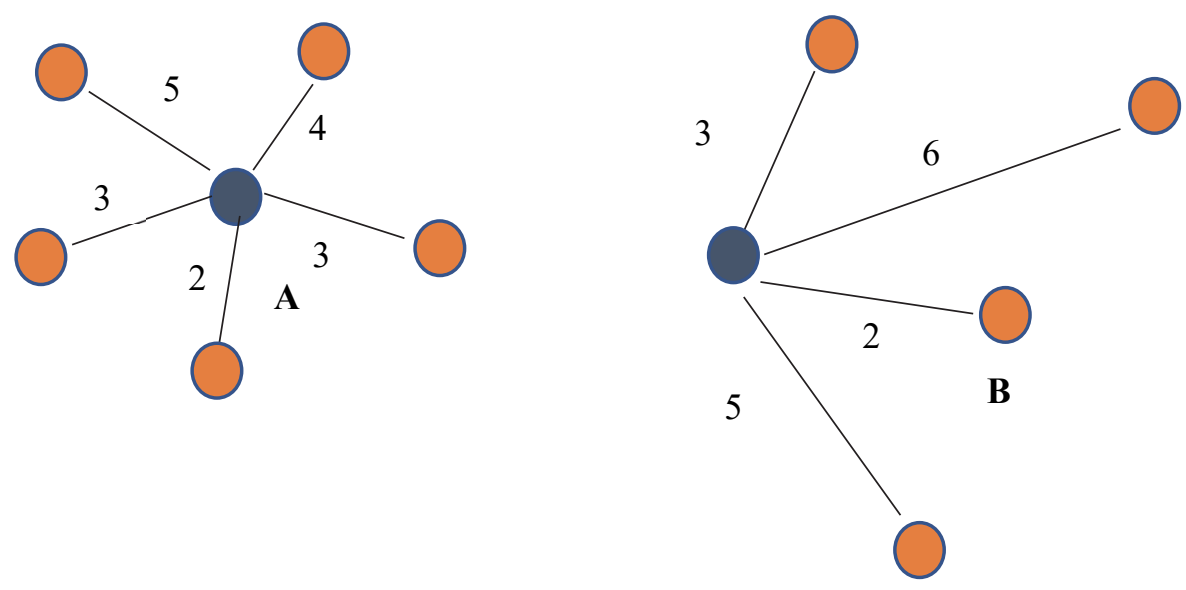

Figure 1.3. Assignment of cities to depots by computing distance 

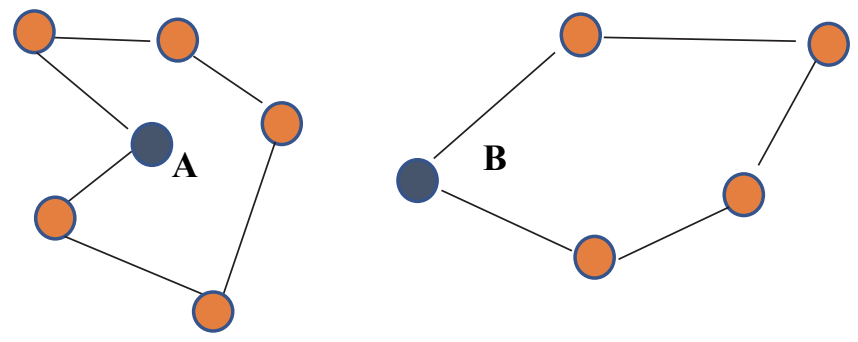

Figure 1.4. Routes formed by taking minimum distance as first choice

In all the above figures MDVRP is shown and the goal is to visit all the cities by covering minimum distance. Here we cover it by calculating the distances from depots to cities.

\section{Nearest neighbor function}

1) Each customer/city is assigned to the nearest depot.

2) Routes are made by traversing the vehicles over the cities (initial solution is made).

3) In order to get a desirable result local improvement method is applied to the routes initially formed.

Above mentioned method in the diagrams is applied to find routes which exist at minimum distance from one another. Each depot serves the designated list of customers identified according to the distance to each depot. Here the numbers of vehicles are generally equal to the number of depots. The tour length generated by this method is similar to the traditional approach. This method could process thousands of customers in seconds, along with the property of a scalability which is becoming increasingly important as networks expand in size. The solution of the MDVRP could obtain using an exact, heuristic or meta-heuristic method. Plus, it could be single objective or multiobjectives. The section 2 of the paper includes a review on the exact methods and in section 3 discuss the heuristic and meta-heuristic techniques used by various researchers focusing on different variants of the MDVRP.

\section{Exact Methods}

The exact methods are designed to solve problems to their optimality. Yet, they are not very ideal for NP-hard problems unless the size of the problem is considerably small. Different researches have discussed on verities of exact methods for MDVRP and overview of the related literatures are discussed in this section. An exact algorithm with a stronger lower bound for the vehicle flow formulation than those in the previous literature was presented in (Contardo \& Martinelli, 2014). The authors have prepared the MDVRP using a vehicle flow and a set partitioning formulation and most stupendously, have solved 14 open instances found in the relevant past literature. The future studies in this direction could be focused on improving the cutting planes in the cutting planes method employed in the solution process and generalization of k-CEC and SDC cuts which are two families of valid inequalities that can even be utilized in other classes of VRPs and multi-period VRPs (Contardo \& Martinelli, 2014).

The presence of multi-compartments for a MDVRP create better combination in the routing procedure and hence offer a more systematic solution. Nevertheless, the advantages available, the multi-compartment variant of the MDVRP has attracted less attention in the extensive literature up to date. In 2018, (Alinaghian \& Shokouhi, 2018) have developed a hybrid algorithm involving significantly large neighborhood and variable neighborhood search to solve large scale occurrences based on a set of assumptions (Alinaghian \& Shokouhi, 2018) such as:

- Vehicles have multiple compartments

- Each compartment is dedicated to one type of product

- $\quad$ Each customer can be served by multiple vehicles

- Each vehicle is assigned to one depot

- Demands of all customers must be fully met

- Each vehicle starts its tour from a depot and in the end returns to the same depot etc.

Kachitvichyanukul, Sombuntham and Kunnapapdeelert in (Kachitvichyanukul et al., 2015) developed two methods to solve the generalized MDVRP with multiple pickup and delivery requests, by formulating the mathematical model as an extension of Ropke and Pisinger. A generalization of the Capacitated VRP, Multi-Depot Open VRP was addressed by (Soto et al., 2017) through the development of a Multiple Neighborhood Search in 
hybridization with a Tabu Search strategy and then secondly using an ejection chain composed with the capacity to handle several neighborhoods.

Coevolutionary algorithms are a type of evolutionary algorithms arising in the process of simultaneous evolution related to two or more species(De Oliveira et al., 2016). Oliveira et al. in (De Oliveira et al., 2016) have introduced a cooperative coevolutionary algorithm which has the capacity to minimize MDVRP that can be regarded as the first ever study involving such an algorithm. The study also resulted in advantages in parallel evolution strategy environments since the authors have decomposed the MDVRP, making each sub problem in to a single depot VRP in devising the solution.The cost minimization in distribution is a requirement with high demand in devising a vehicle route plan in real life situations and hence is widely studied (Ganepola et al., 2018). Shared depot resources facilitate the route of a vehicle to begin from a depot and terminate at any one of the depots sets while reducing the distance for delivery and fuel consumption. In (J. Li et al., 2018), the authors have conducted a benefit analysis about the shared depot resources for a MDVRP and concluded that the characteristics depot-customer geographic distribution, maximum route distance and the number of depots are the factors that have the most significant influence on the relative performance in the presence of shared resources. (Tohidifard et al., 2018) have suggested a novel robust mathematical model for a MDVRP with time windows to be used by home health care firms. This real-life problem was stated with several assumptions to formulate the mathematical model and was solved using a genetic algorithm and particle swarm optimization. As there is the ability of ordering and having on time medical services on patients locations, they have gained many advantages and according to the solution given in (Tohidifard et al., 2018) it has achieved the desires of patients and also has able to reduce the distance and time taken to travel, the number of vehicles and the transportation costs in a patient's hard time windows.

The Mathematical formulation of the model is as follows.

$\operatorname{Min} \sum_{i=1}^{n} \sum_{j=n+1}^{m+n+1} \sum_{k=1}^{K} c_{i j} x_{i j k}+\sum_{i=n+1}^{m+n+1} \sum_{j=n+1}^{m+n+1} \sum_{k=1}^{K} c_{i j} x_{i j k}+\sum_{j=1}^{n} g_{i} y_{i}$
$u_{i}-u_{j}+q_{k} x_{i j k} \leq q_{k}-d_{1, j}, \forall i, j=1, \ldots, n+m+1, \forall i \in S$
$\sum_{j \in N} \sum_{k=1}^{k} x_{i j k}=2, \sum_{j \in N} \sum_{k=1}^{k} x_{i j k}=1, \quad \forall i \notin S$
$\sum_{i=1}^{n+m+1} x_{i h k}-\sum_{j=1}^{n+m+1} x_{h j k}=0, \quad \forall k \in K \quad, \quad \forall h \in P P$

$\sum_{j=1}^{n} \sum_{i=1}^{n+m+1} x_{i j k}=1, \quad \forall k \in K$

$\sum_{i=n+1}^{n+m+1} x_{i(n+m+1) k}=1, \quad \forall k \in K$

$\mathrm{s}_{\mathrm{ik}}+\mathrm{w}_{\mathrm{ik}}+\mathrm{t}_{\mathrm{ij}}-\mathrm{M}\left(1-\mathrm{x}_{\mathrm{ijk}}\right) \leq \mathrm{s}_{\mathrm{jk}}, \forall \mathrm{i}, \mathrm{j} \in \mathrm{N}, \forall \mathrm{k} \in \mathrm{K}$

$\mathrm{e}_{\mathrm{i}} \leq \mathrm{s}_{\mathrm{ik}} \leq \mathrm{l}_{\mathrm{i}} \quad, \quad \forall \mathrm{i} \in \mathrm{PP} \quad, \quad \forall \mathrm{k} \in \mathrm{K}$

$\operatorname{Cr}\left(\sum_{\mathrm{i} \in \mathrm{PP}} \mathrm{d}_{\mathrm{i}} \sum_{\mathrm{j} \in \mathrm{N}} \mathrm{x}_{\mathrm{ijk}}-\mathrm{q}_{\mathrm{k}} \geq 0\right) \geq \mathrm{DPI}, \quad \forall \mathrm{j} \in \mathrm{N} \quad, \forall \mathrm{k} \in \mathrm{K}$

$\sum_{k=1}^{k} \sum_{j=n+1}^{m+n+1} \sum_{i=1}^{n} x_{j i k}=p$ 


$$
\begin{aligned}
& \sum_{i=1}^{n} x_{i j k} \leq 1, \quad \forall j \in N, \quad \forall k \in K \\
& \sum_{i=1}^{n} \sum_{j=1}^{n} x_{i j k}=0, \quad \forall k \in K \\
& \sum_{i \in N} \sum_{k=1}^{k} x_{j i k} \leq M_{i}, \quad \forall j \in d \\
& x_{i j k} \in\{0,1\} ; y_{j \in d} \in\{0,1\}, \quad \forall i, j \in N, \quad \forall k \in K
\end{aligned}
$$

\section{Notations}

$\mathrm{k}$ - $\quad$ index for vehicles; $\mathrm{k}=1, \ldots, \mathrm{K}$

$\mathrm{i}, \mathrm{j}$ - $\quad$ index of all the nodes in the graph. While $\mathrm{n}$ states number of depots; and $\mathrm{m}$ states

$$
\text { number of patients. } \mathrm{i}, \mathrm{j} \in\{1, \ldots, \mathrm{m}+\mathrm{n}+1\}
$$

$\mathrm{V}$ - $\quad$ set of the vehicles

$\mathrm{N}$ - $\quad$ set of all of the graph nodes, including depots (d), patients (P), and a laboratory

$\mathrm{d}$ - $\quad$ Set of depots; $\mathrm{d}=1, \ldots, \mathrm{n}$

$\mathrm{PP}$ - $\quad$ set of patients; $\mathrm{PP}=1, \ldots, \mathrm{m}$

S - $\quad$ set of patients who need two medical services

$\mathrm{p}$ - $\quad$ number of allowed operating drug depots

$d_{i}$ - fuzzy demand of patient $i$ with a triangular membership function

$\mathrm{q}_{\mathrm{k}}$ - $\quad$ capacity of the vehicle

$\mathrm{w}_{\mathrm{ik}}$ - working time for the doctor/nurse of vehicle $\mathrm{k}$ to service the $\mathrm{i}$-th patient

$c_{i j}$ - distance based cost of traveling from node $i$ to node $j$

$g_{j}-\quad \quad \quad$ cost of operating drug depot $j$

$t_{i j}$ - traveling time from node $i$ to node $j$

$e_{i}$ - $\quad$ earliest service time for the i-th patient

$l_{i}$ - latest service time for the $\mathrm{i}$-th patient

$\mathrm{M}$ - $\quad$ positive large number

DPI - $\quad$ dispatcher preference index, where DPI $\in[0,1]$

$\mathrm{u}_{\mathrm{i}}$ - $\quad$ Artificial variable for constructing the sub-tour elimination constraint

$\mathrm{S}_{\mathrm{ik}}$ - $\quad$ Service starting time of vehicle $\mathrm{k}$ to patient $\mathrm{i}$

$$
\begin{gathered}
y_{j}=\left\{\begin{array}{ccc}
1 & \text { selecting depot } j \\
& 0 & \text { otherwise }
\end{array}\right. \\
x_{i j k}=\left\{\begin{array}{ccc}
1 & \text { if vehicle k travels from patient } \mathrm{i} \text { to patient } \mathrm{j} \\
0 & \text { otherwise }
\end{array}\right.
\end{gathered}
$$

In (Seyyedhasani \& Dvorak, 2018), the authors have developed a method which allows dynamic recalculation of routes involving a dynamic environment in agricultural work. There is amalgamation of Dynamic VRP and MDVRP was used and the proposed solution explained the possibility to modernize field routes for a fleet of vehicles during agricultural field operations very well. The VRPs faced by different organizations or companies are usually distinguished based on the additional constraints related to various operational aspects such as environmental regulations, labour laws, politics, contracts with customers, markets etc. Such VRPs are generally identified as Rich Vehicle Routing Problems (RVRP).

In 2019, Kramer, Cordeau and Lori (Kramer et al., 2019) proposed a solution to a RVRP having multiple depots using a multi-start iterated local search algorithm. The algorithms was main into a real life problem faced by a 
logistics provider who delivers pharmaceutical products to healthcare facilities in Tucay and analyzed with respect to having heterogeneous fleet of vehicles, flexible time windows, periodic demands, incompatibilities between vehicles and customers, a maximum duration for the routes and a maximum number of customers per route. The solutions presented in (Eneko Osaba et al., 2019) have addressed the Multi-Depot RVRP for real world problems on a drug distribution problem faced due to a newspaper distribution problem with recycling policy and a pharmacological waste collection in 2017 and 2019 respectively, which were the very first times that such two problems were addressed in the history.

Following table includes a summary of the researches that have introduced exact solution techniques to solve MDVRP, the variety of constraints considered, exact method of solution presented, and the real-life situation considered in formulation of the problem.

Table 1. Summary of MDVRPs presenting exact methods of solution from 2011-2019

\begin{tabular}{|c|c|c|c|c|}
\hline $\mathrm{S} / \mathrm{N}$ & Authors & Nature of constraint & Method of solution & Real-life application \\
\hline 1 & $\begin{array}{l}\text { Contardo and Martinelli } \\
\text { (Contardo \& Martinelli, } \\
\text { 2014) }\end{array}$ & $\begin{array}{l}\text { Total transportation } \\
\text { cost }\end{array}$ & Cutting plane method & $\begin{array}{l}\text { Transportation } \\
\text { network }\end{array}$ \\
\hline 2 & $\begin{array}{l}\text { Yücenur and Demirel } \\
\text { (Yücenur \& Demirel, } \\
\text { 2011) }\end{array}$ & $\begin{array}{l}\text { Total traveled distance } \\
\text { between each depot and } \\
\text { the customers } \\
\text { which are assigned to } \\
\text { the depot. }\end{array}$ & $\begin{array}{l}\text { Geometric shape } \\
\text { based genetic } \\
\text { clustering technique }\end{array}$ & $\begin{array}{l}\text { Transportation } \\
\text { network }\end{array}$ \\
\hline 4 & $\begin{array}{l}\text { Oliveira et al. (De Oliveira } \\
\text { et al., 2016) }\end{array}$ & $\begin{array}{l}\text { Total transportation } \\
\text { cost }\end{array}$ & $\begin{array}{l}\text { Problem } \\
\text { decomposition } \\
\text { approach and } \\
\text { solution by } \\
\text { cooperative } \\
\text { coevolutionary } \\
\text { algorithm }\end{array}$ & $\begin{array}{l}\text { Transportation } \\
\text { network }\end{array}$ \\
\hline 5 & $\begin{array}{l}\text { Kachitvichyanukul, } \\
\text { Sombuntham and } \\
\text { Kunnapapdeelert } \\
\text { (Kachitvichyanukul et al., } \\
\text { 2015) }\end{array}$ & $\begin{array}{l}\text { Variety of constraints to } \\
\text { meet multiple pickup } \\
\text { and delivery requests } \\
\text { such as total } \\
\text { transportation cost, } \\
\text { number of vehicles, } \\
\text { demand etc. }\end{array}$ & $\begin{array}{l}\text { Particle swarm } \\
\text { optimization with } \\
\text { solution } \\
\text { representations, SD2 } \\
\text { and SD3 }\end{array}$ & $\begin{array}{l}\text { Transportation } \\
\text { network }\end{array}$ \\
\hline 6 & $\begin{array}{l}\text { Soto et al. (Soto et al., } \\
\text { 2017) }\end{array}$ & $\begin{array}{l}\text { Minimize the total } \\
\text { traveling length } \\
\text { satisfying the following } \\
\text { constraints: }\end{array}$ & Tabu search strategy & $\begin{array}{l}\text { Transportation } \\
\text { network }\end{array}$ \\
\hline & & $\begin{array}{l}\text { each route starts at any } \\
\text { depot and finishes at } \\
\text { the last visited } \\
\text { customer, } \\
\text { each customer must be } \\
\text { visited by exactly one } \\
\text { vehicle, } \\
\text { the total demand of the } \\
\text { customers on the route } \\
\text { of any vehicle cannot } \\
\text { exceed its capacity, } \\
\text { the total length of each } \\
\text { vehicle route must not } \\
\text { exceed the length } \\
\text { limit. }\end{array}$ & & \\
\hline 7 & $\begin{array}{l}\text { Alinaghian \& Shokouhi } \\
\text { (Alinaghian \& Shokouhi, } \\
\text { 2018) }\end{array}$ & $\begin{array}{l}\text { Minimization of the } \\
\text { number of vehicles and } \\
\text { minimization of the } \\
\text { total traversed routes. }\end{array}$ & $\begin{array}{l}\text { Adaptive large } \\
\text { neighborhood search } \\
\text { and variable } \\
\text { neighborhood search }\end{array}$ & $\begin{array}{l}\text { Transportation } \\
\text { network }\end{array}$ \\
\hline 8 & $\begin{array}{l}\text { Ganepola et al. (Ganepola } \\
\text { et al., 2018) }\end{array}$ & $\begin{array}{l}\text { Minimization of cost } \\
\text { associated in } \\
\text { distribution }\end{array}$ & $\begin{array}{l}\text { Gravity model and } \\
\text { determination of a } \\
\text { Hamiltonian cycle } \\
\text { using Lingo software }\end{array}$ & $\begin{array}{l}\text { Distribution of } \\
\text { bottles and cans from } \\
\text { Lion Brewery Ceylon } \\
\text { PLC., Biyagama. }\end{array}$ \\
\hline
\end{tabular}




\begin{tabular}{|c|c|c|c|c|}
\hline 9 & Li et al. (J. Li et al., 2018) & $\begin{array}{l}\text { Minimizing delivery } \\
\text { distance and fuel } \\
\text { consumption }\end{array}$ & $\begin{array}{l}\text { Hybrid genetic } \\
\text { algorithm with } \\
\text { daptive local search }\end{array}$ & $\begin{array}{l}\text { Transportation } \\
\text { network }\end{array}$ \\
\hline 10 & $\begin{array}{l}\text { Tohidifard et al. } \\
\text { (Tohidifard et al., 2018) }\end{array}$ & $\begin{array}{l}\text { Minimizing the } \\
\text { distance and time of the } \\
\text { travelling tour, the } \\
\text { number of vehicles and }\end{array}$ & $\begin{array}{l}\text { Genetic algorithm } \\
\text { and Particle Swarm } \\
\text { Optimization }\end{array}$ & $\begin{array}{l}\text { MDVRP with time } \\
\text { windows for home } \\
\text { health care firms }\end{array}$ \\
\hline 11 & $\begin{array}{l}\text { Seyyedhasani \& } \\
\text { Dvorak(Seyyedhasani \& } \\
\text { Dvorak, 2018) }\end{array}$ & $\begin{array}{l}\text { the transportation cost. } \\
\text { Reallocation and } \\
\text { rescheduling of the } \\
\text { paths that create the in- } \\
\text { field route for each } \\
\text { vehicle }\end{array}$ & $\begin{array}{l}\text { Dynamic MDVRP } \\
\text { approach }\end{array}$ & $\begin{array}{l}\text { Agricultural field } \\
\text { work }\end{array}$ \\
\hline 12 & $\begin{array}{l}\text { Cordeau \& Lori (Kramer et } \\
\text { al., 2019) }\end{array}$ & $\begin{array}{l}\text { Maximum duration for } \\
\text { the routes and a } \\
\text { maximum number of } \\
\text { customers per route }\end{array}$ & $\begin{array}{l}\text { Multi-start iterated } \\
\text { local search approach }\end{array}$ & $\begin{array}{l}\text { Deliver } \\
\text { pharmaceutical } \\
\text { products to } \\
\text { healthcare facilities } \\
\text { in Tuscany }\end{array}$ \\
\hline 14 & $\begin{array}{l}\text { Osaba et al. (Eneko Osaba } \\
\text { et al., 2019) }\end{array}$ & $\begin{array}{l}\text { Minimize all costs } \\
\text { associated with the } \\
\text { routes }\end{array}$ & $\begin{array}{l}\text { Discrete and } \\
\text { Improved Bat } \\
\text { Algorithm }\end{array}$ & $\begin{array}{l}\text { Pharmacological } \\
\text { waste collection }\end{array}$ \\
\hline
\end{tabular}

\section{Heuristic and Meta-Heuristic Methods}

The existing literature presents solutions for MDVRP through analytical, heuristic and meta-heuristic techniques. Even though the objective of the analytical techniques is to find the accurate solutions, it is not practically viable as fast solutions should be made in large scale. Due to the NP-hardness of the MDVRP, The researchers, find it more tractable on giving solutions based on heuristic and meta-heuristic techniques and due to the NP-hardness of the MDVRP. A combined Multi-Depot Hub-Location Vehicle Routing model for network planning of parcel service which simultaneously determined the number, location, service areas, routes from demand points to depots and vice versa and the number and locations of hubs and routes of depot-hub and hub-hub transports was studied by the authors of (Wasner \& Zäpfel, 2004) in 2011.

The MDVRP has two robust hybrid genetic algorithms. One use initial solution generated by a random process and the other one utilize an initialization procedure incorporated by the Clarke and Wright saving method and the nearest neighbor heuristic. The authors of (Mirabi et al., 2010) have developed three hybrid heuristic algorithms which combine components from constructive heuristic search and improvement techniques that are stochastic in order to solve a MDVRP. This is the first application of hybrid heuristics to solve a MDVRP and its success was apparent by the fact that it has outperformed one of the best-known existing heuristic. A variant of the MDVRP, the min-max Split Delivery MDVRP with Minimum Service Time Requirement (min-max SDMDVRP-MSTR) was solved using a heuristic approach by Wang et al. which operates in the following three stages (X. Wang et al., 2016).

1) Initialize a feasible solution without splits.

2) Improve the longest routes by splitting service times

3) Ensure all minimum service time requirements are satisfied

The MDVRP was studied from a view of location routing and periodic routing problems by Prodhon in (Prodhon, 2011) and a hybrid heuristic solution was developed based on an algorithm known as Randomized Extended Clarke and Write Algorithm (RECWA), where periodic VRPs and location routing problems are combined to result in a feasible solution.

(Aras et al., 2011) presents an extension of the classical MDVRP based on a realistic problem faced by a firm associated with durable goods industry which aims to collect products from dealers. The authors have formulated two mixed integer linear programming models for this problem and solved using a Tabu Search based heuristic approach. Hazardous material transportation has caught attention in the recent years due to the intense demand and potential threats to the public. In 2017, (Du et al., 2017) have proposed a fuzzy bilevel programming model for a MDVRP transporting hazardous materials, aimed at minimizing the total expected transportation risk involved in delivery. Accordingly, four fuzzy simulation based heuristic algorithms was obtained as the best solution.

Customer allocation is a strategy that can be used to solve MDVRP. This approach divides MDVRP of large scale into different single depot VRPs which reduces the study on problems complexity of the MDVRP algorithm. The 
nearest-depot approach, cluster approach and the border customer approach are various customer allocation strategies that can be employed. Using meta heuristics to solve a MDVRP developed by a customer allocation strategy is realistic and (Tu et al., 2014) proposes a bilevel Voronoi diagram based meta heuristic to find answers on a large scale MDVRP. Authors of (J. Li et al., 2015) has proposed another MDVRP related to simultaneous deliveries and pickups which solved using a meta-heuristic approach based on an iterated local search. It was observed from the tested computational results that the suggested approach outperforms the previous methods and is better than using large neighborhood search, particle swarm optimization or ant colony optimization.

Moreover, an integer programming based heuristic model was proposed in (Gulczynski et al., 2011) by Gulczynski et al. with respect to a MDVRP considering split delivery. A novel real life problem related to heterogeneous fleet, a Multi-Depot Multi-Period VRP was studied in (Mancini, 2016) by Simona Mancini. The problem was investigated for a diverse fleet comprising of vehicles with different capacities, features and hourly costs through formulation of a mixed integer programming with the intention of reducing the total delivery cost. An interesting difference observed in comparison to the classical VRPs is that, every customer may or will not be served by all the vehicles or neither from all the depots (Mancini, 2016). The problem was solved using an Adaptive Large Neighbourhood Search based Matheuristic approach involving variety of destroy operators. The future research in this direction is suggested to be conducted addressing the cases of introduction of customer product compatibilities which makes the situation even more realistic.

(Jabir et al., 2017) have studied about the MDGVRP focusing on the minimization of the economic and emission costs in a capacitated MDVRP. Integer linear programming models were proposed which could be solved using LINGO solver in small scale instances and using Ant Colony Optimization (ACO) based meta-heuristic in both large and small scale instances. Furthermore, the performance of the ACO based meta-heuristic was improved by combining with a variable neighbourhood search. This can be regarded as the former study conducted on Capacitated MDGVRPs and the authors suggest future research focusing on manufacturing related emissions and logistics emissions influence on the route design, combining facility planning and routing, production scheduling and routing in integrated decision making of the green VRP and the impact of the emission details on the supply chain decisions such as pricing of the products.

In (Afshar-Nadjafi \& Afshar-Nadjafi, 2017), a time-dependent MDVRP is considered with the objective of minimizing the total diverse fleet cost under the assumption that the travel time between locations is dependent on the departure time. The authors have utilized a mixed integer programming model in formulation of the problem and a heuristic process was presented as the solution procedure. It was then evaluated on a large sample of test problems, viz. 180 and have confirmed to result in a satisfying solution. The Multi-Depot Green Vehicle Routing Problems (MDGVRP) focuses on reducing the vehicle emissions other than on usual factors such as cost reduction, profit increament, travel time reduction etc. In 2019, a MDGVRP was developed by (Y. Li et al., 2019) which minimizes revenue, cost, time and emission and solved by application of an improved ant colony optimization algorithm.

The corresponding models developed can be described as follows (Jabir et al., 2017).

Model 1. Total economic cost reduction model.

$$
\text { Economic cost }=\sum_{v=1}^{v} \sum_{i=1}^{m+n} \sum_{j=1}^{m+n} x_{i j v} l_{i j} C_{v a r}+\sum_{v=1}^{v} \sum_{i=1}^{m} \sum_{j=m+1}^{m+n} x_{i j v} C_{f i x}
$$

Model 2. Total emission cost reduction model

Minimize

$$
\text { Emission cost }=\sum_{\mathrm{v}=1}^{\mathrm{v}} \sum_{\mathrm{i}=1}^{\mathrm{m}+\mathrm{n}} \sum_{\mathrm{j}=1}^{\mathrm{m}+\mathrm{n}} \mathrm{l}_{\mathrm{ij}} \mathrm{P}_{\mathrm{CO}_{2}} \mathrm{w}_{\mathrm{CO}_{2}} \mathrm{~V}_{\text {eff }} \mathrm{W}_{\mathrm{ijv}} \mathrm{w}_{\mathrm{p}}+\sum_{\mathrm{v}=1}^{\mathrm{v}} \sum_{\mathrm{i}=1}^{\mathrm{m}+\mathrm{n}} \sum_{\mathrm{j}=1}^{\mathrm{m}+\mathrm{n}} \mathrm{x}_{\mathrm{ijv}} \mathrm{l}_{\mathrm{ij}} \mathrm{P}_{\mathrm{CO}_{2}} \mathrm{w}_{\mathrm{CO}_{2}} \mathrm{~V}_{\text {eff }} \frac{\mathrm{w}_{\text {Curb }}}{\mathrm{k}}
$$

Model 3. Integrated total cost reduction model where the combined influence of emission as well as economic cost on route planning is analyzed

$$
\text { Total cost }=\text { Economic cost }+ \text { Emission cost }
$$




$$
\begin{gathered}
=\sum_{v=1}^{V} \sum_{i=1}^{\mathrm{m}+\mathrm{n}} \sum_{\mathrm{j}=1}^{\mathrm{m}+\mathrm{n}} \mathrm{x}_{\mathrm{ijv}} \mathrm{l}_{\mathrm{ij}} \mathrm{C}_{\mathrm{var}}+\sum_{\mathrm{v}=1}^{\mathrm{V}} \sum_{\mathrm{i}=1}^{\mathrm{m}} \sum_{\mathrm{j}=\mathrm{m}+1}^{\mathrm{m}+\mathrm{n}} \mathrm{x}_{\mathrm{ijv}} \mathrm{C}_{\mathrm{fix}}+ \\
\sum_{\mathrm{v}=1}^{\mathrm{V}} \sum_{\mathrm{i}=1}^{\mathrm{m}} \sum_{\mathrm{j}=1}^{\mathrm{n}} \mathrm{l}_{\mathrm{ij}} \mathrm{P}_{\mathrm{CO}_{2}} \mathrm{w}_{\mathrm{CO}_{2}} \mathrm{~V}_{\mathrm{eff}} \mathrm{w}_{\mathrm{ijv}} \mathrm{w}_{\mathrm{p}}+\sum_{\mathrm{v}=1}^{\mathrm{n}} \sum_{\mathrm{i}=1}^{\mathrm{m}} \sum_{\mathrm{j}=1}^{\mathrm{n}+\mathrm{n}} \mathrm{x}_{\mathrm{ijv}} \mathrm{l}_{\mathrm{ij}} \mathrm{P}_{\mathrm{CO}_{2}} \mathrm{w}_{\mathrm{CO}_{2}} \mathrm{~V}_{\text {eff }} \frac{\mathrm{w}_{\mathrm{Curb}}}{\mathrm{k}}
\end{gathered}
$$

Where,

Decision variables:

$x_{i j v}=1$, if vehicle $v$ travels from node $i$ to node $j, i=1, \ldots, n+m, j=1, \ldots, m+n, v=1, \ldots, V$ and $x_{i j v}$ $=0$, otherwise

$\mathrm{w}_{\mathrm{ijv}}-\quad$ the number of units of cargo carried by the vehicle $v$ from node $\mathrm{i}$ to node $\mathrm{j}$

Indices:

$\mathrm{i}, \mathrm{j}$ - $\quad$ node indices

v - vehicle indices

Parameters:

$\mathrm{m}$ - $\quad$ upper bound on the number of depots

$\mathrm{n}$ - number of customers

V - maximum number of vehicles

$l_{\mathrm{ij}}$ - distance from node $\mathrm{i}$ to node $\mathrm{j}$

$\mathrm{C}_{\mathrm{var}} \quad$ variable vehicle operating cost per unit distance

$\mathrm{C}_{\mathrm{fix}}$ - fixed cost for a vehicle

$V_{\text {eff }} \quad$ volume of fuel consumption per unit distance per unit vehicle weight

$\mathrm{w}_{\mathrm{p}}$ - $\quad$ weight of each delivered product

$\mathrm{w}_{\mathrm{CO}_{2}}$ - weight of $\mathrm{CO}_{2}$ emission per litre consumption of fuel

$\mathrm{P}_{\mathrm{CO}_{2}}-\quad$ average price per unit weight of $\mathrm{CO}_{2}$

$\mathrm{k}$ - $\quad$ ratio of vehicle volume to curb weight

$\mathrm{w}_{\text {Curb }}$ - average gross weight per vehicle through travelling on each route

$d_{j}$ - demand of customer node $j$

In (Soeanu et al., 2020), the authors presented a cost effective learning-based heuristic technique intricated through an illustrative case study. The solution was developed by keeping track on minimizing the routing and potential costs which might occur due to possibilities of vehicle breakdown and failures on cargo delivery.

Table 2 presents an overview of the constraints, solution methods and the real-life applications considered in developing the heuristic and meta-heuristic solutions for MDVRP during the last five years.

\begin{tabular}{|c|c|c|c|c|}
\hline $\mathrm{S} / \mathrm{N}$ & Authors & Constraints considered & Solution technique & Real-life application \\
\hline 1 & $\begin{array}{llr}\text { Mirabi } & \text { et } & \text { al. } \\
\text { (Mirabi } & \text { et } & \text { al., } \\
2010) & & \end{array}$ & Minimizing delivery time. & $\begin{array}{l}\text { Constructive } \\
\text { Heuristic search and } \\
\text { improvement } \\
\text { technique. }\end{array}$ & $\begin{array}{l}\text { Transportation } \\
\text { network. }\end{array}$ \\
\hline
\end{tabular}

Table 2. Summary of MDVRPs presenting heuristic and meta-heuristic methods of solution from 2015-2020 
2 Prodhon Constraints on customers to be

(Prodhon, 2011)

4 Aras et al. (Aras et al., 2011)

$5 \quad$ Tu et al. (Tu et al., 2014)

$6 \quad \mathrm{Li}$ et al. (J. Li et al., 2015)

$7 \quad$ Gulczynski et al. (Gulczynski et al., 2011)

9 Mancini

(Mancini, 2016)

Minimizing the total delivery cost.

Meeting pickups and delivery simultaneously.

10 Nadjafi et al. (Afshar-Nadjafi \& Afshar-

Nadjafi, 2017)

11 Du et al. (Du et al., 2017)

13 Li et al. (Y. Li et al., 2019)

15 Jabir et al. (Jabir et al., 2017)

6 Soeanu et al. Minimizing the routing and (Soeanu et al., potential costs.

vehicles, route and total load of the route.

Optimize route of a homogeneous capacitated vehicles.

Minimizing the total heterogeneous fleet cost and Hard time window constraints for the customers and limitation on maximum number of vehicles.

Minimizing total expected transportation risk.

Minimizing revenue, cost, time and emission.

Minimizing economic and emission costs.
Hybrid heuristic Transportation

approach.

network.

Tabu search based heuristic approach.

Collection of cores from dealers by firms in durable goods industry.

Bilevel Voronoi Transportation based meta-heuristic network. approach

Meta-Heuristic approach based on Transportation iterated local search.

Heuristic approach.

Transportation network.

Adaptive large Transportation neighbourhood network. search based MetaHeuristic.

Constructive

Transportation Heuristic approach. network.

Improved ant colony algorithm.

simulation

based heuristic

Serving customers with a fleet of vehicles in a pregiven road network.

Transportation network.

LINGO solver and ant colony optimization based meta-heuristic.

Transportation network.

Transportation network.

\section{Conclusion}

Finding the best routes for distributor vehicles that optimizes the use of vehicles, routes and minimizes operational cost, subject to vehicle travel-time restrictions and capacity conditions is the focus of MDVRP which provides more benefits to both user and operator in comparison to VRP. Having a few depots under MDVR make salesman's work convenient and drastically reduced lead time increases satisfied customers. In addition, the clusters help drivers to clearly focus on their assigned routes removing redundant and unnecessary work. More organized distribution channels, shorter lead time, less stress on drivers and planners are the other benefits of MDVR over VRP. More research has solved another issue of VRP i.e. travelling salesmen problem applying different techniques and methods. Rather than taking exact methods like branch and bound method or computational complexities, MDVRP can be used to reduce cost for distance with effective techniques such as heuristic methods in swarm intelligence to gain optimal solutions. In a situation where demand distribution of the product or service is changed, the importance of MDV routing analysis increases. More researches should emphasize in the future on 
the suitable models to check the profitability of maintaining one single warehouse vehicle routing arrangement or multiple depot vehicle routing systems. In the short run, operating one single and big warehouse allocation could be more profitable than creating several small warehouses whereas in the long run, multiple-depot vehicle routine can be more profitable. Therefore, future researchers can implement more heuristic search methods to address the existing issues and give optimal solutions with MDVRP.

\section{Acknowledgments}

It is with pleasure and gratitude I mention my supervisor Dr G. H. J. Lanel of the Department of Mathematics, University of Sri Jayewardenepura and Dr. Z. A. M. S. Juman, Department of Mathematics, Faculty of Science, University of Peradeniya. Both their invaluable guidance, assistance, encouragement and sense of responsibility made this research possible. They were always behind me whenever I needed direction and helped me to complete this project successfully. I truly appreciate their commitment and valuable time spent on this project.

\section{References}

Alinaghian, M., \& Shokouhi, N. (2018). Multi-depot multi-compartment vehicle routing problem, solved by a hybrid adaptive large neighborhood search. Omega, 76, 85-99. https://doi.org/10.1016/j.omega.2017.05.002

Aras, N., Aksen, D., \& Tuğrul, Tekin, M. (2011). Selective multi-depot vehicle routing problem with pricing. Transportation Research Part C: Emerging Technologies, 19(5), 866-884. https://doi.org/10.1016/j.trc.2010.08.003

Contardo, C., \& Martinelli, R. (2014). A new exact algorithm for the multi-depot vehicle routing problem under capacity and route length constraints. Discrete Optimization, 12, 129-146. https://doi.org/10.1016/j.disopt.2014.03.001

De Oliveira, F. B., Enayatifar, R., Sadaei, H. J., Guimarães, F. G., \& Potvin, J. Y. (2016). A cooperative coevolutionary algorithm for the Multi-Depot Vehicle Routing Problem. Expert Systems with Applications, 43, 117-130. https://doi.org/10.1016/j.eswa.2015.08.030

Du, J., Li, X., Yu, L., Dan, R., \& Zhou, J. (2017). Multi-depot vehicle routing problem for hazardous materials transportation: A fuzzy bilevel programming. Information Sciences, 399, 201-218. https://doi.org/10.1016/j.ins.2017.02.011

Ganepola, D. D., Jayarathna, N. D., \& Madhushani, G. (2018). An intelligent cost optimized central warehouse and redistribution root plan with truck allocation system in Colombo region for Lion Brewery Ceylon PLC. Journal of Sustainable Development of Transport and Logistics, 3(2), 66-73. https://doi.org/10.14254/jsdtl.2018.3-2.4.

Gulczynski, D., Golden, B., \& Wasil, E. (2011). The multi-depot split delivery vehicle routing problem: An integer programming-based heuristic, new test problems, and computational results. Computers \& Industrial Engineering, 61(3), 794-804. https://doi.org/10.1016/j.cie.2011.05.012

Jabir, E., Panicker, V. V., \& Sridharan, R. (2017). Design and development of a hybrid ant colony-variable neighbourhood search algorithm for a multi-depot green vehicle routing problem. Transportation Research Part D: Transport and Environment, 57, 422-457. https://doi.org/10.1016/j.trd.2017.09.003

Jayarathna, N., Lanel, J., \& Juman, Z. A. M. S. (2020). Five years of multi-depot vehicle routing problems. Journal of Sustainable Development of Transport and Logistics, 5(2), 109-123. https://doi.org/10.14254/jsdt1.2020.52.10 .

Jayarathna, N., Lanel, J., Juman, S., (2019). A contemporary Recapitulation of Major Findings on Vehicle Routing Problems: Models and Methodologies. International Journal of Recent Technology and Engineering, 8(2S4), 581-585. https://doi.org/10.35940/ijrte.B1115.0782S419

Kachitvichyanukul, V., Sombuntham, P., \& Kunnapapdeelert, S. (2015). Two solution representations for solving multi-depot vehicle routing problem with multiple pickup and delivery requests via PSO. Computers \& Industrial Engineering, 89, 125-136. https://doi.org/10.1016/j.cie.2015.04.011

Kramer, R., Cordeau, J. F., \& Iori, M. (2019). Rich vehicle routing with auxiliary depots and anticipated deliveries: An application to pharmaceutical distribution. Transportation Research Part E: Logistics and Transportation Review, 129, 162-174. https://doi.org/10.1016/j.tre.2019.07.012

Li, J., Pardalos, P. M., Sun, H., Pei, J., \& Zhang, Y. (2015). Iterated local search embedded adaptive neighborhood selection approach for the multi-depot vehicle routing problem with simultaneous deliveries and pickups. Expert Systems with Applications, 42(7), 3551-3561. https://doi.org/10.1016/j.eswa.2014.12.004 
Li, J., Wang, R., Li, T., Lu, Z., \& Pardalos, P. M. (2018). Benefit analysis of shared depot resources for multi-depot vehicle routing problem with fuel consumption. Transportation Research Part D: Transport and Environment, 59, 417-432. https://doi.org/10.1016/j.trd.2018.01.026

Li, Y., Soleimani, H., \& Zohal, M. (2019). An improved ant colony optimization algorithm for the multi-depot green vehicle routing problem with multiple objectives. Journal of Cleaner Production, 227, 1161-1172. https://doi.org/10.1016/j.jclepro.2019.03.185

Mancini, S. (2016). A real-life Multi Depot Multi Period Vehicle Routing Problem with a Heterogeneous Fleet: Formulation and Adaptive Large Neighborhood Search based Matheuristic. Transportation Research Part C: Emerging Technologies, 70, 100-112. https://doi.org/10.1016/j.trc.2015.06.016

Mirabi, M., Fatemi Ghomi, S. M. T., \& Jolai, F. (2010). Efficient stochastic hybrid heuristics for the multi-depot vehicle routing problem. Robotics and Computer-Integrated Manufacturing, 26(6), 564-569. https://doi.org/10.1016/j.rcim.2010.06.023

Nadjafi, B. A, \& Nadjafi, A, A. (2017). constructive heuristic for time-dependent multi-depot vehicle routing problem with time-windows and heterogeneous fleet. Journal of King Saud University. Engineering Sciences, 29(1), 29-34. https://doi.org/10.1016/j.jksues.2014.04.007

Osaba, E., Yang, X. S., Fister, I., Del Ser, J., Lopez-Garcia, P., \& Vazquez-Pardavila, A. J. A. (2019). Discrete and Improved Bat Algorithm for solving a medical goods distribution problem with pharmacological waste collection. Swarm and Evolutionary Computation, 44, 273-286. https://doi.org/10.1016/j.swevo.2018.04.001

Seyyedhasani, H., \& Dvorak, J. S. (2018). Dynamic rerouting of a fleet of vehicles in agricultural operations through a Dynamic Multiple Depot Vehicle Routing Problem representation. Biosystems Engineering, 171, 63-77. https://doi.org/10.1016/j.biosystemseng.2018.04.003

Soeanu, A., Ray, S., Berger, J., Boukhtouta, A., \& Debbabi, M. (2020). Multi-depot vehicle routing problem with risk mitigation: Model and solution algorithm. Expert Systems with Applications, 145, 11309. https://doi.org/10.1016/j.eswa.2019.113099

Soto, M., Sevaux, M., Rossi, A., \& Reinholz, A. (2017). Multiple neighborhood search, tabu search and ejection chains for the multi-depot open vehicle routing problem. Computers \& Industrial Engineering, 107, 211-222. https://doi.org/10.1016/j.cie.2017.03.022

Tohidifard, M., Tavakkoli-Moghaddam, R., Navazi, F., \& Partovi, M, A. (2018). Multi-Depot Home Care Routing Problem with Time Windows and Fuzzy Demands Solving by Particle Swarm Optimization and Genetic Algorithm. https://doi.org/10.1016/j.ifacol.2018.08.318

Tu, W., Fang, Z., Li, Q., Shaw, S.-L., \& Chen, B, A. (2014). bi-level Voronoi diagram-based metaheuristic for a large-scale multi-depot vehicle routing problem. Transportation Research Part E: Logistics and Transportation Review, 61, 84-97. https://doi.org/10.1016/j.tre.2013.11.003

Wang, X., Golden, B., Wasil, E., \& Zhang, R. (2016). The min-max split delivery multi-depot vehicle routing problem with minimum service time requirement. Computers \& Operations Research, 71, 110-126. https://doi.org/10.1016/j.cor.2016.01.008

Yücenur, G. N., \& Demirel, N. (2011). Expert Systems with Applications, 38(9), 11859-11865. https://doi.org/10.1016/j.eswa.2011.03.077

\section{Copyrights}

Copyright for this article is retained by the author(s), with first publication rights granted to the journal.

This is an open-access article distributed under the terms and conditions of the Creative Commons Attribution license (http://creativecommons.org/licenses/by/4.0/). 